\title{
Lengua y cultura: una propuesta teórico-práctica para cerrar la brecha ${ }^{1}$
}

\author{
Language and Culture: A Theoretical \\ and Practical Classroom Suggestion for Closing the Gap
}

\author{
Cecilia Silva \\ Institute for Excellence of Higher Education, Tohoku University, \\ Kawauchi Campus 41, Aoba-ku, Sendai-shi, Japan \\ e-mail: cecilin2006@yahoo.com
}

\begin{abstract}
In the present article we revise the concepts of culture and intercultural competence, include the five dimensions of the concept of culture proposed by Moran (2001) -products, practices, communities, persons, and perspectives- in Byram's (1991) model, and apply the new model in the design of a class of Spanish as a foreign language. In the class described in this article we attempt to go beyond the concept of culture as mere content, and work with the concept of intercultural competence as social and cultural practices.
\end{abstract}

Keywords: Spanish as a foreign language, cultural elements, intercultural communicative competence

\section{INTRODUCCIÓN}

La enseñanza de un idioma extranjero es, por definición, multicultural e intercultural. Traer una lengua extranjera al aula significa conectar a los estudiantes con un mundo culturalmente diferente del de ellos, lo cual constituye un potencial digno de ser explotado con fines didácticos. Por ello, los objetivos de la clase de lengua ya no

\footnotetext{
${ }^{1}$ El presente artículo forma parte del proyecto "Developing multimodal learning materials for Spanish as a Foreign Language based on the balance of communicative and structural approaches and on the concept of intercultural communicative competence" (Grant-in-aid, $n^{\circ} 25370614$, Japan Society for the Promotion of Science 2013-2015).
} 
se definen solamente en términos de la adquisición de la competencia comunicativa, sino que es necesario hablar de competencia comunicativa intercultural.

Tanto en el paso de una postura multicultural a una intercultural, como también en el paso de un modelo teórico a la práctica en el aula, el punto básico es encontrar el modo de facilitar a los estudiantes la interacción con alguna parte desconocida de otra sociedad y su cultura. La finalidad es relativizar la comprensión que los estudiantes tienen de sus propios valores culturales, sus creencias y comportamientos, e invitarlos a investigar y observar otras prácticas.

Hasta cierto punto, diseñar clases para enseñar lenguas con una perspectiva intercultural es una cuestión de aprovechar oportunidades en un sentido sistemático: partir de una teoría, plantear un diseño intercultural de contenidos y, lo más ambicioso, evaluar los resultados según criterios claros y explícitos.

En el presente artículo comenzaremos revisando los conceptos teóricos de cultura e interculturalidad, sugeriremos un modelo de trabajo en el aula como puente entre la teoría y el trabajo práctico en el aula y analizaremos los resultados obtenidos.

\section{PRIMERA PARTE: DE LA TEORÍA...}

Un gran número de profesores de lenguas extranjeras entienden que la adquisición de una lengua no se limita al dominio de las cuatro destrezas lingüísticas. Por ejemplo, el Marco común europeo de referencia para las lenguas agrega interacción, mediación y comprensión cultural como destrezas adicionales (Council of Europe, 2001). Algunos investigadores perciben la comprensión cultural como la quinta destreza en la adquisición de una lengua (Kramsch, 1993, 2003). Otros la consideran un elemento central del currículum (Lafayette, 2003). En realidad, no podemos hablar de una competencia completa en una lengua si no dominamos el contexto cultural en el que ella ocurre. En esta parte, vamos a revisar los conceptos de cultura e interculturalidad.

\section{1. ¿A QUÉ SE REFIERE EL CONCEPTO DE CULTURA?}

Entre las múltiples definiciones del término cultura podemos mencionar aquellas que se refieren a la perspectiva desde la cual vemos el mundo, un sistema compartido para entender el mundo, un marco para percibir, creer, crear, evaluar y actuar. Algunas acepciones del término cultura acentúan la característica de construcción colectiva. Geertz (1973) pone énfasis en el aspecto interaccional del concepto, cuando indica que, mientras el conocimiento se limita a lo individual, la cultura es algo compartido por los seres humanos que participan en la vida de una comunidad. Y no 
podemos dejar de mencionar la tradicional definición de cultura como un témpano (Brembeck, 1977, en Lázár, 2007, p. 7) porque nos proporciona dos caras del concepto: lo que no podemos ver a simple vista -sistemas de comunicación, creencias, valores, etc.- se manifiesta en forma concreta y visible en las obras de arte, la lengua, la comida, las costumbres. Numerosas definiciones se apoyan en esa doble faceta del término cultura, como, por ejemplo, la conceptualización de Edward Ty$\operatorname{lor}^{2}$ (citado en Khan, s/f):

La cultura o civilización, en sentido etnográfico amplio, es aquel complejo que incluye el conocimiento, las creencias, el arte, la moral, el derecho, las costumbres y cualesquiera otros hábitos y capacidades adquiridos por el hombre en cuanto miembro de la sociedad [...] Para Tylor, los elementos de una cultura evolucionan y se relacionan con otros elementos, por ello su concepto de cultura es amplio, para incluir las relaciones entre diversos elementos a lo largo de la historia.

También Boas (1930, citado en Khan, s/f) conceptualizó la cultura como una multiplicidad de dos caras:

La cultura incluye todas las manifestaciones de los hábitos sociales de una comunidad, las reacciones del individuo en la medida en que se ven afectadas por las costumbres del grupo en que vive, y los productos de las actividades humanas en la medida que se vean determinadas por dichas costumbres.

La complejidad del concepto de cultura se ha visto reflejada en numerosísimas aproximaciones desde diversas disciplinas que conceptualizan la cultura como algo primario, elemental; como un término relativo y general; como pertenencia a un grupo; como cuestionamiento, como algo individual y colectivo al mismo tiempo.

Moran (2001, pp. 1-11) nos ofrece una síntesis clara y concisa de las muy variadas perspectivas desde las cuales podemos considerar el concepto de cultura:

- como civilización, es decir, como un reflejo de los productos y prácticas de los individuos en la historia de la comunidad;

- como comunicación, incluyendo todos los códigos y sistemas que la gente usa para comunicarse e interactuar;

- como un concepto general que no hace referencia a una cultura determinada, sino a los componentes que pueden aplicarse a cualquier cultura y que nos sirven para hacer comparaciones;

- en términos de comunicación intercultural: aquí la cultura es vista como un proceso en el que los individuos de diversas culturas entran en contacto y se esfuerzan por lograr una comunicación exitosa;

- como interacción de grupos o comunidades con diferentes niveles de poder, influencia, autoridad, privilegios;

\footnotetext{
${ }^{2}$ Todas las traducciones que aparecen en el texto están hechas por la autora del presente artículo.
} 
- como una construcción humana dinámica: esta perspectiva pone el énfasis en que la cultura no es un cúmulo estático de conocimiento, sino una construcción activa resultante de las relaciones interpersonales;

- en términos biológicos o de psicología evolutiva: esta perspectiva acentúa la importancia de los aspectos relacionados con las emociones como una base compartida por todas las culturas.

A continuación, vamos a poner nuestra atención en la comunicación entre culturas y en el concepto de interculturalidad.

\section{2. ¿A QUÉ SE REFIERE EL CONCEPTO DE INTERCULTURALIDAD?}

La interculturalidad hace referencia a la interacción entre hablantes de lenguas y culturas distintas. Esta interacción nos lleva al concepto de comunicación intercultural, expresión utilizada por primera vez por el antropólogo Edward Hall (1959) en su libro The Silence Language:

La comunicación intercultural es aquella que resulta de la interacción entre hablantes de lenguas y culturas diferentes. Los interlocutores que participan en encuentros interculturales han experimentado previamente procesos de socialización distintos y han desarrollado marcos de conocimiento diferentes (citado en Diccionario de términos clave de $E L E, \mathrm{~s} / \mathrm{f})$

Si estamos de acuerdo en que la cultura proporciona el contexto de una lengua y que el conocimiento de los significados culturales de esa lengua es indispensable para usar apropiadamente las destrezas lingüísticas, se pondrán en juego al menos dos culturas, la del aprendiente y la de la lengua meta. Esto nos lleva a proponer un estudio de la lengua desde una perspectiva intercultural, para apreciar diferencias, contrastes y similitudes sin entrar en juicios estereotípicos y con una actitud de curiosidad y aceptación.

Actualmente coexisten dos movimientos culturales aparentemente opuestos: por un lado, la globalización, sostenida por una total libertad mercantil; por otro, la reafirmación de la identidad regional, defensora de lo local (Estévez Coto \& Fernández de Valderrama, 2006). Después de las guerras mundiales, los países europeos hacen un esfuerzo para mejorar el entendimiento entre países y culturas y esto se vuelca en proyectos de formación laboral y en programas académicos, a lo que se suman los movimientos migratorios humanos, ya sean por causas políticas o económicas. Todo ello resulta en una pintura multicultural que requiere una especial consideración. El concepto de multiculturalidad, la existencia de varias culturas, obtiene desde el campo educativo una propuesta de interacción cultural que da origen al concepto de interculturalidad: el esfuerzo de lograr la interacción y la comunicación entre culturas diferentes y de preparar a los estudiantes para esta situación. 
Según el Marco común europeo de referencia para las lenguas, la consciencia intercultural se forma de la siguiente manera:

El conocimiento, la percepción y la comprensión de la relación entre el mundo de origen y el mundo de la comunidad objeto de estudio (similitudes y diferencia distintivas) producen una consciencia intercultural que incluye, naturalmente, la conciencia de la diversidad regional y social en ambos mundos, que se enriquece con la consciencia de una serie de culturas más amplia de la que conlleva la lengua materna y la segunda lengua, lo cual contribuye a ubicar a ambas en su contexto. (capítulo 5, punto 5.1.1.3)

Byram, Nichols \& Stevens (2001) consideran que, si bien muchos programas de contenidos se refieren a la importancia de la enseñanza de cultura, y más recientemente, de la competencia intercultural, todavía la práctica es insuficiente. La teoría orientada a explicar la integración de lengua y cultura desarrollada especialmente por Kramsch (1993) ha proporcionado una base renovada para la práctica. Sin duda, los trabajos de Byram \& Buttjes (1991) y de Byram, Nichols \& Stevens (2001) han ampliado el horizonte al ofrecer una discusión completa del significado de la competencia comunicativa intercultural e identificar los modos de formularla y de evaluarla.

El presente trabajo intenta sugerir algunas ideas para tender un puente entre la teoría y la práctica de la enseñanza de lengua y cultura.

\section{SEGUNDA PARTE: ... A LA PRÁCTICA}

\subsection{APLICACIÓN DE CONCEPTOS: IDEALES Y PROBLEMAS}

La cultura no vive en la mente de los individuos, sino en la interacción humana (Geertz, 1973; Brody, 2003). Los participantes en la clase de lengua extranjera tienen sus propias perspectivas culturales y sus propias formas de ver el mundo y van a adquirir otra lengua que les transmitirá una nueva perspectiva. En este contexto tan particular y cambiante, el docente se ve en la tarea de poner en práctica la obvia integración de lengua y cultura.

Enseñar elementos culturales en la clase de lengua a veces no parece tarea fácil. En un estudio llevado a cabo sobre la percepción que tienen los docentes de Bélgica, Bulgaria, España, Grecia, México, Polonia y Suecia en cuanto a la enseñanza de la cultura y el tiempo dedicado a tal actividad, los resultados indican que, si bien los docentes están de acuerdo en incrementar la enseñanza de la cultura, este deseo no se refleja en la realidad de sus clases (Castro \& Sercu, 2005). Las causas mencionadas incluyen la falta de tiempo, no solamente para dedicar algunas clases a actividades culturales, sino también para planear dichas actividades. Otra razón indicada por los docentes es el currículum, fuertemente orientado a la enseñanza y práctica de destrezas lingüísticas y a la preparación de exámenes; por consiguiente, no hay 
tiempo para contenidos culturales. Una tercera razón es la carencia de materiales y recursos adecuados para la enseñanza de cultura: los libros de texto no contienen información cultural, no integran las dimensiones lingüística y cultural, y en muchos casos contienen estereotipos. La siguiente razón mencionada por los docentes es la falta de preparación para enseñar temas culturales. Un número reducido de docentes de Grecia indicó específicamente la carencia de entrenamiento en temas intery multiculturales. Un grupo de docentes se refirió a la falta de interés y motivación de los estudiantes por la dimensión cultural de la lengua, por considerarla una pérdida de tiempo. Paralelamente, los docentes indicaron que el nivel lingüístico de los estudiantes es insuficiente para una discusión cultural. Esta última razón es la elegida por la autora del presente trabajo como desafío para plantear la integración de las dimensiones lingüística y cultural en el aula de español como lengua extranjera a nivel A1.

\subsection{JUSTIFICACIÓN Y OBJETIVOS}

Un punto de partida para vincular la lengua y la cultura en el aula es considerar que la lengua es parte de la cultura y al mismo tiempo una herramienta para su transmisión. Damen (2003) indica que la comunicación supone algo más que palabras, involucra códigos no verbales, modelos, productos, temas, y -sobre la división entre lengua y cultura en la clase- sostiene que sería como jugar el juego de la lengua sin conocer las reglas.

Nos proponemos promover la familiaridad de los estudiantes con la cultura, la civilización y la visión del mundo de los países donde se habla la lengua de estudio, ayudar a los estudiantes a lograr la apertura de sus mentes y una disposición positiva hacia culturas no conocidas y a desarrollar una comprensión más amplia de su propia identidad y cultura.

En el momento de diseñar actividades basadas en el modelo expuesto, tomamos dos puntos de partida que consideramos básicos para la integración de la dimensión cultural y la dimensión de las destrezas:

a. Los ejercicios gramaticales y las actividades comunicativas pueden convertirse en espacios significativos para el diálogo intercultural (Kramsch, 1998).

b. La tarea que nos proponemos es facilitar la interacción de los aprendientes con alguna pequeña parte de otra sociedad y sus culturas, con el propósito de relativizar la comprensión de sus propios valores, creencias y comportamientos, y motivarlos para investigar lo diferente, tanto en su ambiente físico circundante como también en el contexto amplio y globalizado en el que vivimos (Byram, Nichols \& Stevens, 2001).

En un intento de integrar el estudio de la cultura y la práctica de las destrezas lingüísticas hemos combinado elementos de dos modelos, Byram (1991) y Moran 
(2001), que consideraremos para la producción de material y el diseño de actividades.

El modelo de Byram, El proceso de enseñanza de lengua y cultura ${ }^{3}$, combina dos posibilidades: por un lado, el uso de la lengua materna de los estudiantes para hacer un análisis comparativo de significados culturales propios y externos; por otro, la enseñanza de una lengua extranjera como materia de estudio y como medio para experimentar fenómenos culturales de otras sociedades.

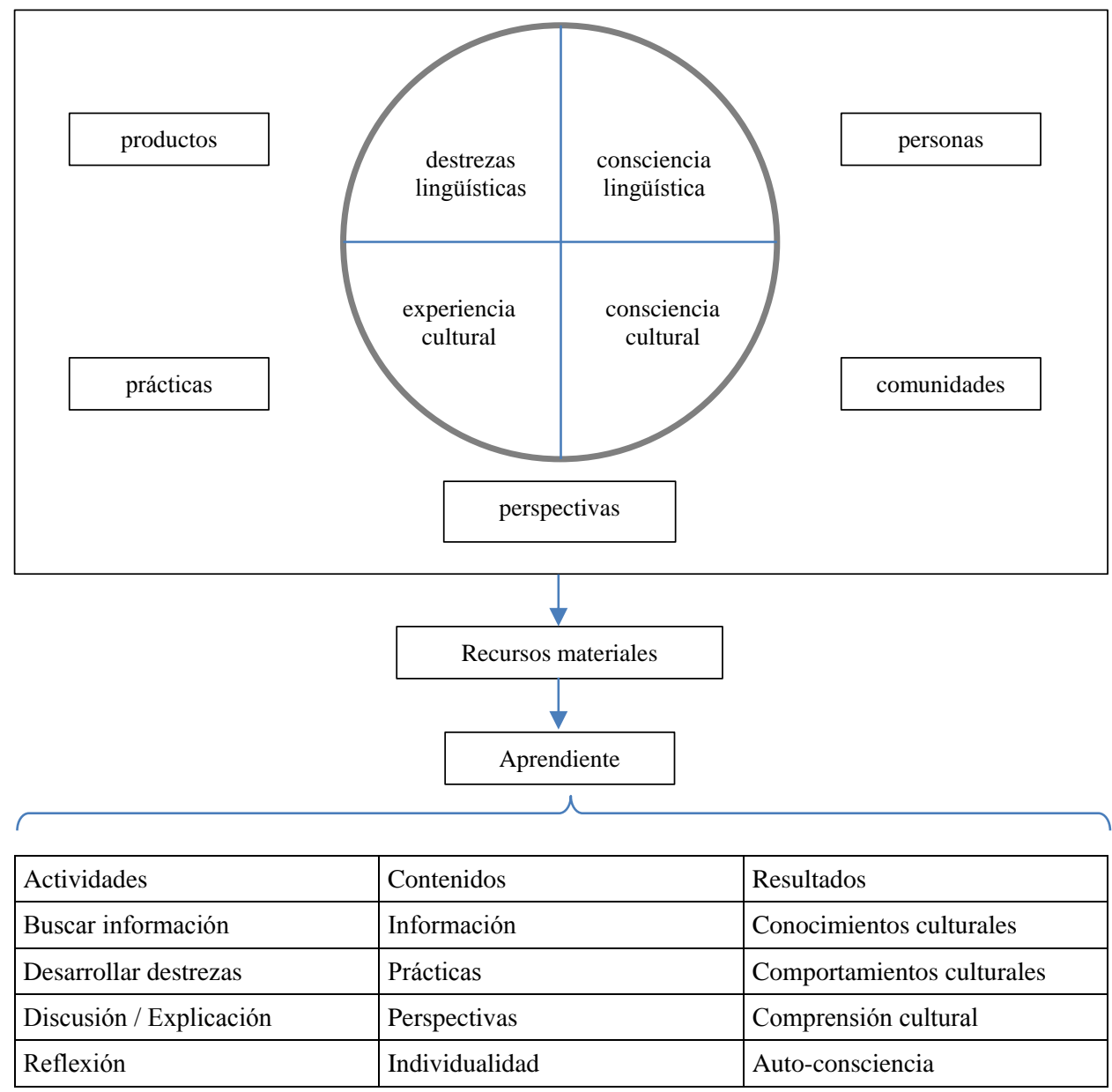

Fig. 1. Modelo basado en los trabajos de Byram (1991) y Moran (2001) para diseñar una clase de integración de lengua y cultura

\footnotetext{
${ }^{3}$ The language and culture teaching process (Byram, 1991, p. 20).
} 
La propuesta de Moran, Lengua-y-Cultura ${ }^{4}$, enfatiza que la lengua es un producto de la cultura, con un rol muy especial: la lengua es necesaria para conocer una cultura en su totalidad y para crear, identificar, organizar y nombrar productos culturales, es una ventana a la cultura.

El modelo teórico para el trabajo práctico que logramos (véase figura 1), nos permite diseñar una clase de español de nivel A1 en la cual vamos más allá de los elementos con contenidos culturales, llegamos a los aspectos interculturales y encontramos un vínculo entre los temas de índole cultural y las destrezas lingüísticas.

\subsection{COMPONENTES DEL MODELO DE BYRAM (1991)}

El modelo de Byram (1991) contiene cuatro elementos que se benefician mutuamente, y componen un proceso que va desde el aprendizaje de la lengua en el sentido de adquisición de destrezas lingüísticas hasta la experiencia directa de una cultura extranjera:

1. Aprendizaje de la lengua a través de la práctica de destrezas lingüísticas: este componente acentúa la característica de la lengua como fenómeno social y proporciona a los estudiantes la oportunidad de usar la lengua de los hablantes nativos.

2. Consciencia de la lengua: este componente centra la atención de los estudiantes en las similitudes y las diferencias entre la lengua materna y la lengua en estudio. Los estudiantes comienzan a comprender las conexiones entre la lengua y los fenómenos culturales.

3. Consciencia cultural: este componente considera los aspectos no lingüísticos de la lengua y proporciona a los estudiantes la ocasión de reflexionar sobre su propia cultura y hacer comparaciones con la cultura de la lengua de estudio.

4. Experiencia cultural: se trata de la experiencia directa con la cultura de la lengua de estudio. Si no fuera posible hacer viajes educativos, los docentes y sus asistentes han de esforzarse en proporcionar dichas experiencias en la clase.

\subsection{ELEMENTOS DEL MODELO PROPUESTO POR MORAN (2001)}

Los elementos de la propuesta de Moran (2001) comprenden dos dimensiones: la lengua en la cultura y la lengua en la sala de clase, e indican que la lengua es al mismo tiempo parte de la cultura y una herramienta para conocerla.

1. Lengua y productos culturales. La lengua es la herramienta para manipular todos los objetos de una cultura: desde objetos y herramientas hasta instituciones y otras construcciones como el arte, la literatura, la arquitectura y la

\footnotetext{
${ }^{4}$ Language-and-Culture (Moran, 2001, pp. 34-47).
} 
música. Al mismo tiempo, la lengua es un producto cultural que adquiere forma tangible al hablarse, escribirse, adquirir nuevas palabras y estructuras y dejar de lado otras.

2. Lengua y prácticas culturales. Las prácticas culturales requieren el uso de la lengua, en particular la lengua apropiada para participar en cada práctica. Las circunstancias sociales, los participantes, el tema, el lugar y muchos otros factores tienen influencia en la naturaleza de la lengua usada. La lengua puede ser muy complicada, como la requerida en algunos países en caso de un funeral, o muy simple, como la requerida para el cumpleaños de un amigo. En todas las ocasiones, para participar apropiadamente, se necesita usar las palabras adecuadas en el momento adecuado.

3. Lengua y perspectivas culturales. La lengua revela perspectivas culturales: usamos la lengua para comprender y para referirnos a percepciones, valores, actitudes y creencias. Cuando examinamos el significado de palabras y unidades fraseológicas comprendemos que están tan ligadas a la cultura de una comunidad, que la gramática es insuficiente para revelarnos su contenido. Estas perspectivas no son inmediatamente obvias y requieren una profunda explicación y ejemplificación.

4. Lengua y comunidades culturales. Cuando situamos la lengua en determinadas comunidades o grupos observamos variaciones y especificidades relacionadas con el grupo y su circunstancia. En combinación con circunstancias y prácticas culturales, las comunidades o grupos definen normas para el uso de la lengua y la adaptan a la interacción que los ocupa.

5. Lengua y personas. La lengua, como la cultura, no es solamente colectiva, sino también personal. Los seres humanos comparten una lengua, pero cada persona la usa según su idiosincrasia, sus experiencias, su identidad y/o el grupo al que pertenece.

Con respecto a los recursos materiales, una gran parte de la mediación entre los estudiantes y el mundo transmitido a través de la lengua reside en los materiales. No se discute la conveniencia de usar un determinado libro de texto en la clase; sin embargo, a menudo los textos son criticados por ser rígidos, por no contemplar los intereses de los estudiantes, por presentar imágenes fragmentadas y a veces estereotípicas de las culturas y por no permitir suficiente espacio para la creatividad del docente y del estudiante (Davcheva \& Sercu, 2005). Por ello, los profesores entrevistados en el trabajo de Davcheva \& Sercu en Bélgica, Bulgaria, España, Grecia, México, Polonia y Suecia se manifestaron a favor de un amplio uso de materiales adicionales, aduciendo las siguientes ventajas: introducir variedad en las actividades y en los temas, incrementar la motivación de los estudiantes presentando temas relacionados con sus intereses, ofrecer no solamente temas universales y atemporales sino también información actual, proporcionar autenticidad con elementos de situaciones reales. 
En el caso que describimos en el presente trabajo, consideramos los elementos de las propuestas de Byram (1991) y Moran (2001), y también el nivel de los estudiantes y los temas ya estudiados con el fin de diseñar la actividad que describiremos a continuación.

\section{TRABAJO EN AL AULA DE ESPAÑOL COMO LENGUA EXTRANJERA}

La actividad que aquí se describe se llevó a cabo en tres cursos de español como lengua extranjera ( 30 estudiantes en cada curso) en una clase ( 90 minutos).

La clase comenzó con un producto cultural, la presentación de la novela $\mathrm{El}$ amor en los tiempos del cólera (2008) y 23 minutos de la película basada en dicha novela. A continuación, los estudiantes trabajaron en grupos para buscar información sobre García Márquez y responder a preguntas desarrollando y practicando destrezas lingüisticas: $s e r+$ nacionalidad/profesión/adjetivos y sustantivos para describir personas. Como en la película hay una escena de un funeral, los estudiantes, el asistente de la clase y la docente hablaron sobre las expresiones especiales que se usan en un funeral y los saludos, lo cual forma parte de la consciencia lingüística. Luego, los estudiantes y el asistente de la clase -colombiano- indicaron las diferencias entre un funeral en Colombia y uno en Japón: qué llevan los asistentes al funeral y cómo se visten, lo cual constituye parte de la consciencia cultural e indica prácticas culturales. La experiencia cultural se desarrolló en el diálogo informal entre los estudiantes, el asistente de clase y la docente. Los estudiantes mencionaron los aspectos culturales que les llamaron la atención, los elementos que indican una época pasada (productos culturales) y elaboraron preguntas sobre los elementos culturales que no entendieron. La docente y el asistente de clase aclararon y explicaron todo lo necesario. En cuanto a la lengua y comunidades culturales, los estudiantes preguntaron sobre la expresión "Amén" usada en la misa. Con respecto a la relación entre lengua y personas, los estudiantes se refirieron a la diferencia en el uso de la lengua de dos personajes: el padre de Fermina, brusco e interesado en la posición social del pretendiente de su hija, y Florentino, de hablar pausado, sereno y romántico.

A continuación, hubo otro momento de práctica de destrezas lingüisticas. En primer lugar, repasaron los números para responder cuántos años, meses y días esperarían al amor de su vida. En segundo lugar, los estudiantes usaron su imaginación e investigaron vocabulario nuevo para responder qué harían si sus progenitores no les permitieran casarse con la persona que quieren. Contestaron con oraciones creativas y gramaticalmente correctas: "Yo huyo de mi casa y no regreso", "Yo negocio personalmente con el padre", "Salgo de copas con el padre", o "Yo me resigno porque lo considero mi destino".

Los estudiantes usaron elementos culturales (una película y los contenidos allí mostrados, información y prácticas culturales) para llevar a cabo actividades de 
búsqueda de información, desarrollar destrezas, usar la imaginación, reflexionar y sostener una discusión simple (para esto último usaron en parte la lengua materna).

Los resultados de la actividad los clasificamos en términos de comprensión de comportamientos culturales que los estudiantes hayan podido observar y lo que ellos consideran que han aprendido. Algunas de sus respuestas son las siguientes:

Tabla 1. Comportamientos y conocimientos culturales observados por los estudiantes

\begin{tabular}{|l|l|}
\hline \multicolumn{1}{|c|}{ Comportamientos culturales } & \multicolumn{1}{c|}{ Conocimientos culturales } \\
\hline - Aprovechar la misa para entregar cartas. & - Las diferencias y similitudes entre Japón y Co- \\
- Enviar un mechón de pelo a la persona amada. & lombia con respecto a funerales y religión. \\
- En el pasado, el casamiento y otros temas fami- & - Los rituales de la misa y sus significados. \\
liares no se podían decidir libremente. & - Cultura de América del Sur a fines del siglo XIX: \\
- Expresiones de pésame y vestimenta para fune- & atmósfera, gente, costumbres en el plano afec- \\
rales. & tivo. \\
- Sociedad centrada en el hombre, escasas opcio- & \\
nes para una mujer soltera. & \\
- Comportamientos apasionados: enviar cartas, to- & \\
car un instrumento y llevar flores. & \\
\hline
\end{tabular}

A continuación incluimos las actividades de la clase de español estructurada para integrar elementos culturales y destrezas lingüísticas que describimos en el presente trabajo.

\section{Actividad 1}

Gabriel García Márquez (1928-2014)

Algunas de las obras del autor:

El coronel no tiene quien le escriba (1961),

Cien años de soledad (1967),

El otoño del patriarca (1975),

El amor en los tiempos del cólera (1985),

Memorias de mis putas tristes (2004).

¿De dónde es Gabriel García Márquez?

¿Cuál es su profesión?

¿Dónde está

(el país de García Márquez)? Márcalo en el mapa.

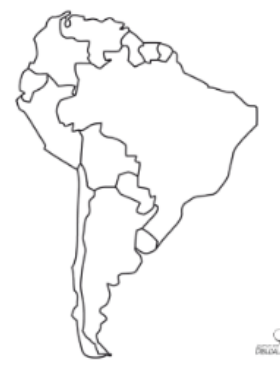


Las actividades se desarrollaron en torno a un fragmento de la película El amor en los tiempos del cólera (2008) basada en la novela homónima.

Actividad 2. Trabaja con tu compañero o compañera y contesta las siguientes preguntas:

1. ¿Cuánto tiempo espera Florentino a Fermina?

2. ¿Cómo es Florentino?

3. ¿Qué hace Florentino? ¿Cuál es su profesión?

4. ¿Cómo es Fermina?

5. Elige otro personaje y di cómo es.

6. ¿Por qué no se casan Florentino y Fermina?

Actividad 3

1. ¿Cómo te comportas en un funeral? ¿qué dices? ¿qué llevas? ¿cómo te vistes?

\begin{tabular}{|c|c|}
\hline En Japón & En Latinoamérica \\
\hline & \\
\hline
\end{tabular}

2. Saludos:

¿Cómo saludas en tu país? A tus amigos, a tus padres, a las personas mayores, etc.
¿Cómo se saluda en Colombia? A los amigos, a los padres, a las personas mayores, etc.

3. ¿Qué aspectos culturales te han llamado la atención?

4. ¿Qué elementos indican una época pasada?

5. Piensa en los aspectos culturales que has visto es esta parte de la película y elabora preguntas.

Actividad 4. ¿Cuánto tiempo esperarías tú al amor de tu vida?

\section{Actividad 5. Imagina}

Chicos: el padre de tu novia no le permite casarse contigo, ¿qué harías?

Chicas: tu padre no te permite casarte con tu novio, ¿qué harías?

\section{Actividad 6}

1. ¿Qué comportamientos te han llamado la atención?

2. ¿Qué has aprendido en la actividad de hoy?

3. Actividad de hoy: menciona puntos negativos y puntos positivos.

4. Tu impresión sobre la clase de hoy 
Actividad 7. Discusión

Los procesos de adquisición del lenguaje y de la competencia cultural no son independientes sino que se entrelazan desde el momento en que un ser humano entra en una sociedad, al nacer o en el vientre materno, según sea la consideración filosófica de "entrar en sociedad" (Ochs, 1996, citado en Hall, 2012). En concordancia con esa afirmación, en el proceso de aprender una lengua y su cultura, los estudiantes comienzan a comprender la cultura ya no como información sobre una sociedad y sus prácticas sino como un marco dentro del cual la gente se comunica (Scarino, 2010, citado en Hall, 2012).

La literatura consultada indica que hay un esfuerzo real por integrar en el currículum de lenguas extranjeras un enfoque que lleve a los estudiantes a analizar el marco cultural de una lengua y los elementos interculturales necesarios para una comunicación significativa. Sin embargo, no encontramos experiencias para estudiantes de nivel A1 que combinen destrezas lingüísticas y comunicación oral (una discusión a un nivel muy limitado). Por ello creemos que la experiencia aquí descrita puede resultar útil para otros educadores. Tanto en el diseño de las tareas como en el desarrollo de las mismas en el aula, consideramos los siguientes aspectos:

a. Intentamos guiar a los estudiantes a usar los contenidos léxicos y gramaticales aprendidos para manejar contenidos culturales: hablar y preguntar sobre ellos. En las dos primeras actividades los estudiantes trabajaron con la bibliografía de Gabriel García Márquez y con las características de los personajes principales de la película. La importancia de esta parte del trabajo es la aplicación de las herramientas lingüísticas aprendidas para resolver cuestiones relacionadas con el contenido de la película El amor en los tiempos del cólera.

b. Pusimos énfasis en que los estudiantes prestaran atención no solamente a los fenómenos culturales de la lengua extranjera que estudian sino también a los propios. En esta parte, recurrimos a la lengua materna de los estudiantes para hacer comparaciones de prácticas y comportamientos entre su cultura y la cultura latinoamericana, y también del nivel de formalidad lingüística requerido según las circunstancias.

c. Buscamos el modo de relacionar los comportamientos y los hechos observados en la película El amor en los tiempos del cólera con la vida propia. Encontramos la relación recurriendo a la imaginación: los estudiantes usaron elementos lingüísticos aprendidos y los combinaron con elementos nuevos (con la ayuda de la docente o de los asistentes de cátedra, cuando era necesario) para expresar sutilezas que están más allá del uso cotidiano de la lengua.

En la bibliografía consultada no encontramos indicaciones concretas referentes al uso de la lengua materna de los estudiantes o al uso exclusivo de la lengua extranjera en estudio. Uno de los aspectos más importantes de la clase aquí descrita fue el 
uso natural de la lengua materna de los estudiantes cuando el nivel adquirido en la lengua española no resultaba suficiente. El uso de la lengua materna sin crear interferencias y en combinación con la lengua extranjera se debe, en gran medida, a la mirada dual de los estudiantes: la cultura propia y el marco cultural del idioma extranjero.

\section{CONCLUSIONES}

El presente trabajo constituye una sugerencia para la integración de lengua y cultura en el aula de español como lengua extranjera. Una lectura crítica y un análisis exhaustivo de las respuestas de los estudiantes participantes nos permitiría no solamente mejorar el trabajo, sino también incluir este tipo de actividades en el programa de contenidos anuales en forma más periódica o sistemática. Las actividades aquí detalladas se desarrollaron en una clase (90 minutos), lo cual nos obligó a trabajar muy rápidamente. Esto contribuyó a lograr una clase sumamente activa, aunque tal vez, con más tiempo, se hubiera extendido la discusión y el análisis de elementos culturales. A pesar de las limitaciones, esperamos que algunas ideas, debidamente adaptadas al contexto, sean útiles a otros docentes en su intento de integrar estudios culturales y destrezas lingüísticas en el nivel A1. 


\section{BIBLIOGRAFÍA}

Brody, J. (2003). Linguistic Anthropological Perspective in Second Language Curriculum. En: D. Lange \& M. Paige (Eds.), Culture as the Core. Perspectives on Culture in Second Language Learning (pp. 37-51). Connecticut: Information Age Publishing.

Byram, M. (1991). Teaching Culture and Language: Towards an Integrated Model. En: D. Butjes \& M. Byram (Eds.), Mediating Languages and Cultures: Towards an Intercultural Theory of Foreign Language Education. Philadelphia: Multilingual Matters Ltd.

Byram, M., Nichols, A. \& Stevens, D. (2001). Developing Intercultural Competence in Practice. New York: Multilingual Matters Ltd.

Castro, P. \& Sercu, L. (2005). Objectives of Foreign Language Teaching and Culture Teaching Time. En: L. Sercu, E. Bandura, P. Castro, L. Davcheva, M. Méndez García \& P. Ryan (Eds.), Foreign Language Teachers and Intercultural Competence. An International Investigation (pp. 19-38). Clevedon: Multilingual Matters Ltd.

Council of Europe (2001). The Common European Framework of Reference for Languages: Learning, Teaching, Assessment. Disponible en http://www.coe.int/t/dg4/linguistic/

Damen, L. (2003). Closing the Language and Culture Gap. An Intercultural Communication Perspective. En: L. Sercu, E. Bandura, P. Castro, L. Davcheva, M. Méndez García \& P. Ryan (Eds.), Foreign Language Teachers and Intercultural Competence. An International Investigation (pp. 71-88). Clevedon: Multilingual Matters Ltd.

Davcheva, L. \& Sercu, L. (2005). Culture in Foreign Language Teaching Materials. En: L. Sercu, E. Bandura, P. Castro, L. Davcheva, M. Méndez García \& P. Ryan (Eds.), Foreign Language Teachers and Intercultural Competence. An International Investigation (pp. 90-109). Clevedon: Multilingual Matters Ltd.

Diccionario de términos clave de ELE (s/f). Centro Virtual Cervantes. Disponible en http://cvc. cervantes.es/Ensenanza/biblioteca_ele/diccio_ele/indice.htm

Estévez Coto, M. \& Fernández de Valderrama, Y. (2006). El componente cultural en la clase de E/LE. Madrid: Edelsa.

García Márquez, G. (2008). El amor en los tiempos del cólera. Barcelona: Random House Mondadori S.A.

Geertz, C. (1973). The Interpretation of Cultures. New York: Basic Books Inc.

Hall, J. (2012). Teaching and Researching Language and Culture. Harlow: Pearson Education Limited.

Instituto Cervantes (2002). Marco común europeo de referencia para las lenguas: aprendizaje, enseñanza, evaluación. Disponible en http://cvc.cervantes.es/ensenanza/biblioteca_ele/marco/ cvc_mer.pdf

Kahn, J. (s/f). El concepto de cultura: textos fundamentales. Disponible en http://es.slideshare.net/ emersonbalderas/j-s-kahn-el-concepto-de-cultura-textos-fundamentales

Kramsch, C. (1993). Context and Culture in Language Teaching. Oxford: Oxford University Press.

Kramsch, C. (2003). Teaching Along the Cultural Faultline. En: D. Lange \& M. Paige (Eds.), Culture as the Core. Perspectives on Culture in Second Language Learning (pp. 19-36). Connecticut: Information Age Publishing.

Lafayette, R. (2003). Culture in Second Language and Teaching. En: D. Lange \& M. Paige (Eds.), Culture as the Core. Perspectives on Culture in Second Language Learning (pp. 53-69). Connecticut: Information Age Publishing.

Lázár, I., Huber-Kriegler, M., Lussier, D., Matei, G. \& Peck, C. (2007). Developing and Assessing Intercultural Communicative Competence. A Guide for Language Teachers and Teacher Educators. Graz: Council of Europe Publishing. Disponible en http://book.coe.int

Moran, P. (2001). Teaching Culture. Perspectives in Practice. Boston: Heinle \& Cengage Learning. 
